\title{
Oil Sorption by Heat-Treated Rice Husks
}

\author{
Kudaybergenov KK*, Ongarbayev EK and Mansurov ZA
}

Al-Farabi Kazakh National University, Institute of Combustion Problems, Almaty, Kazakhstan

\begin{abstract}
Rice husks, an agricultural waste, were thermally treated and evaluated as an adsorbent for oil with the goal of being used as a remediation strategy for oil spills of oil based products. The oil sorption capacity was examined of thermally-treated, carbonized rice husks which are mainly composed of silicates. Results showed that the oil sorption capacities of the carbonized rice husks prepared at $700^{\circ} \mathrm{C}$ is $16 \mathrm{~g} / \mathrm{g}$ for heavy crude oil. The microstructure and morphology of the carbonized rice husks were investigated by FTIR spectrometry and Scanning Election Microscope (SEM).
\end{abstract}

\section{Keywords: Oil sorption; Rice husks; Gasoline; Adsorption}

\section{Introduction}

Water preservation implies recovering oils and hydrocarbon oils from water, among other pollutants. When an oil spill occurs on water, it is critical to contain the spill as quickly as possible in order to minimize danger and potential damage to persons, property, and natural resources. Containment equipment is used to restrict the spread of oil and to allow for its recovery, removal, or dispersal. The use of floating barriers is the most commonly used technique to control the spread of oil, whereas sorbents are most often used to remove final traces of oil, or in areas that cannot be reached by skimmers [1].

A number of vegetable by-products from sunflower, rice and maize, as well as the wastes obtained from the processing of grass, leaves, straw and others are utilized as adsorbents. They are insoluble in water, have a good chemical stability and high mechanical strength, have a granular structure, making them a good adsorbent material. Using raw agricultural wastes in such a way is one of the primary research directions in the field of the environmental protection.

Moreover, agricultural by-products have provided to be promising raw materials for the production of carbon content adsorbents. Pyrolysis is a thermo-chemical process which has been widely applied to processing of biomass, gain due to its energy content. Thermal treatment removes the moisture and the volatile matter contents of biomass material. The remarkable differences are mainly in structure, morphology and chemical activity of the final product. The changes in the properties usually lead to high reactivity, and hence, a usage of carbon content material as adsorbent [2-7].

\section{Materials and Method}

The samples were carbonized according to the procedure developed at the Laboratory of Oxidation Hydrocarbon raw material in the Institute of Combustion Problems. The sorption capacity of the heattreated rice husks was evaluated in the case of typical oil with different density: gasoline Ai-80 $\left(\rho=0.734 \mathrm{~g} / \mathrm{cm}^{3}\right)$; heavy crude oil $(\rho=0.937 \mathrm{~g} /$ $\left.\mathrm{cm}^{3}\right)$ and light crude oil $\left(\rho=0.792 \mathrm{~g} / \mathrm{cm}^{3}\right)$. The oil adsorption properties of the samples were evaluated using a simple, easily reproduced, and easily applied procedure [8].

\section{Results and Discussion}

The effect of contact time on the sorption capacity of $\mathrm{TRH}_{700}$ (rice husk was head-treated at $700^{\circ} \mathrm{C}$ ) and $\mathrm{TAS}_{600}$ (apricot stone was heattreated at $600^{\circ} \mathrm{C}$ ) were studied. In previous study, rice husks that heat-treated at $700^{\circ} \mathrm{C}$ and tested for heavy oil achieved the greatest oil adsorption in our experiments $[8,9]$. The results as shown in Figure 1 explains the effect of sorption time on oil uptake and as expected, sorption capacity increases with the contact time from the first $5 \mathrm{mins}$. Also, the Figure 1 shows that it mainly consists of two significant phases: a primary rapid phase and a slow phase. Most of oil uptake occurred at the initial rapid phase, while the second stage contributed to a relatively small uptake before the adsorption reached equilibrium. This initial high rate of oil uptake may be attributed to the greater bare surface existence for adsorption; however, as the time was increased, less adsorption sites were available hence a small amount of oil uptake occurred [10]. This effect may be due to adsorption on first surface which then start to penetrate the inner microscopic voids. One can see comparing the obtained experimental data that the highest sorption ability is exhibited by $\mathrm{TRH}_{700}$, while the lowest is exhibited by TAS ${ }_{600}$, which is likely to be connected with high density of samples [8]. The time to reach equilibrium for crude oil on $\mathrm{TRH}_{700}$ and TAS ${ }_{600}$ were 25 and $35 \mathrm{~min}$, respectively (Figure 1).

Effect of oil film thickness on the sorption capacity of $\mathrm{TRH}_{700}$ was studied. Figure 2 shows that the sorption capacity increases by increasing the oil film thickness. The Figure also shows that the heavy crude oil has the highest sorption capacity until it reaches a maximum value of $(16 \mathrm{~g} / \mathrm{g})$ at oil film thickness of $(5 \mathrm{~mm})$. Light crude oil has the second highest sorption capacity of $(7.03 \mathrm{~g} / \mathrm{g})$ at film thickness of ( $5 \mathrm{~mm})$; finally the lowest sorption capacity is for which is $(5.8 \mathrm{~g} / \mathrm{g})$ at oil film thickness of $(5 \mathrm{~mm})$. The result indicates that the sorption capacity of heat-treated rice husk is enhanced by increase the oil film thickness. The oil film contact sorbent surface to oil is the maximum and inhibits sorbent contact to water to minimum value. i.e., the oil sorption capacity increases as the amount of oil increases. These results are in agreement $[11,12]$ as they have studied the effect of thickness of the oil layer (Figure 2).

*Corresponding author: Kudaybergenov KK, Al-Farabi Kazakh National University, Institute of Combustion Problems, Almaty, Kazakhstan, Tel: 7-727-37733-39; E-mail: kenes_85_85@mail.ru

Received February 14, 2015; Accepted July 16, 2015; Published July 26, 2015

Citation: Kudaybergenov KK, Ongarbayev EK, Mansurov ZA (2015) Oil Sorption by Heat-Treated Rice Husks. J Pet Environ Biotechnol 6: 243. doi:10.4172/21577463.1000243

Copyright: () 2015 Kudaybergenov KK, et al. This is an open-access article distributed under the terms of the Creative Commons Attribution License, which permits unrestricted use, distribution, and reproduction in any medium, provided the original author and source are credited. 
Citation: Kudaybergenov KK, Ongarbayev EK, Mansurov ZA (2015) Oil Sorption by Heat-Treated Rice Husks. J Pet Environ Biotechnol 6: 243. doi:10.4172/2157-7463.1000243

Page 2 of 3

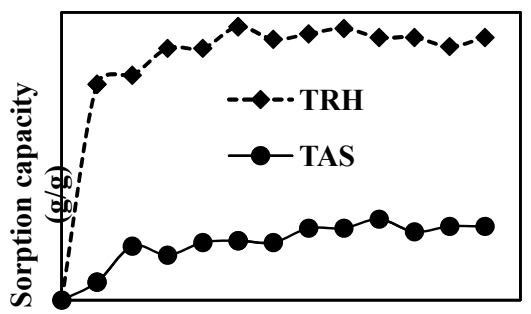

Sorption time (min)

Figure 1: Effect of contact time on sorption of heavy crude oil on $\mathrm{TRH}_{700}$ and TAS $_{600}$

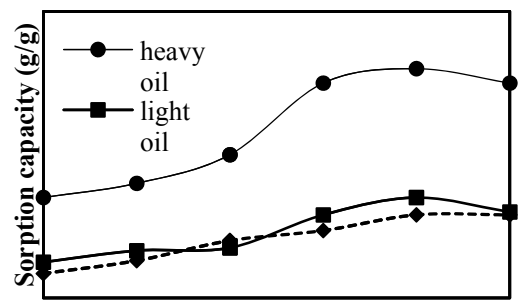

Oil film thickness $(\mathbf{m m})$

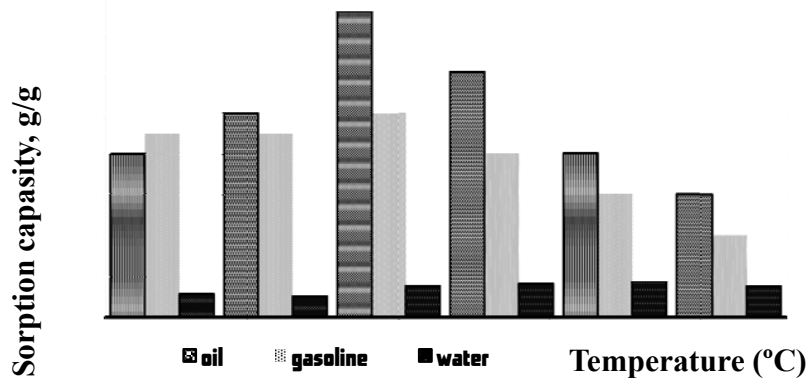

Figure 3: Temperature effect on oil sorption capacity of $\mathrm{TRH}_{700}$.

Figure 3 shows the effect of temperature on oil removal of $\mathrm{TRH}_{700}$. It can be seen that the oil sorption capacity increases with increasing temperature. This increase may be due to the decrease in the oil viscosity at higher temperature to be suitable to penetrate pores and rest between surface roughness until reach maximum value of oil sorption at $25^{\circ} \mathrm{C}$. Meanwhile, at lower temperatures, the high oil viscosity may plug pores and obstacle oil to penetrate and increasing temperature than $25^{\circ} \mathrm{C}$ starts to decrease when oil starts to be very light which leads to release oil from particles again (Figure 3).

The results shown in Figure 4 indicate that the oil sorption and retention properties vary for different oil viscosities. The heavy oil with higher viscosity tends to have higher initial sorption ratio. The high viscosity of heavy oil significantly affects the capillary penetration of oil into the small pores of sorbent material. The results show that the retention behavior of all used oil follows almost the same trend. As shown, there are three zones in each curve: The first zone is the initial stage of release which occurs over the first min and the rate of release is very high during this period; the second or transition zone occurs from 1 to $5 \mathrm{~min}$ over this period which in the rate of release is reduced and the third zone represents the steady state period during this period and additional time will not release any significant amount of oil. Light oil tends to be released from sorbent fast with high release rate compared to the heavy oil. Thus, the curve has only two zones. These results are in agreement with those reported by [13] who studied the sorption desorption on cotton nonwoven fibers (Figure 4).

Infrared spectroscopy provides information on the chemical structure and surface functional groups of the samples. Figure 5a and Figure 5b shows IR spectra of $\mathrm{TRH}_{700}$ and after oil adsorption, respectively. The band with a maximum at $1089 \mathrm{~cm}^{-1}$ is connected with vibrations of the $\mathrm{C}-\mathrm{OH}$ bond and it is dominating in kind and position, as this wave number is characteristic of the stretching vibrations of the siloxane groups [14,15]. After oil adsorption, FT-IR measurement shows (Figure $5 \mathrm{~b}$ ) the pattern with much strong peaks at 2923 and $2853 \mathrm{~cm}^{-1}$ at high intensity, suggesting the oil component combining with hydrophobic groups of heat-treated rice husk [16]

Figure 6 shows SEM micrographs of raw rice husk and heat-treated rice husk $\left(\mathrm{TRH}_{700}\right)$. Figure 6a shows the outer epidermis of $\mathrm{TRH}_{700}$, which is well organized and has a corrugated structure. The crosssections of $\mathrm{TRH}_{700}$ show in Figure $6 \mathrm{~b}$ that many residual pores are distributed within the sample, indicating that the $\mathrm{TRH}_{700}$ is a highly porous material with a large internal surface area [8]. The rice husk might have become broken up during thermal decomposition of organic matter, thus leaving a highly porous structure.

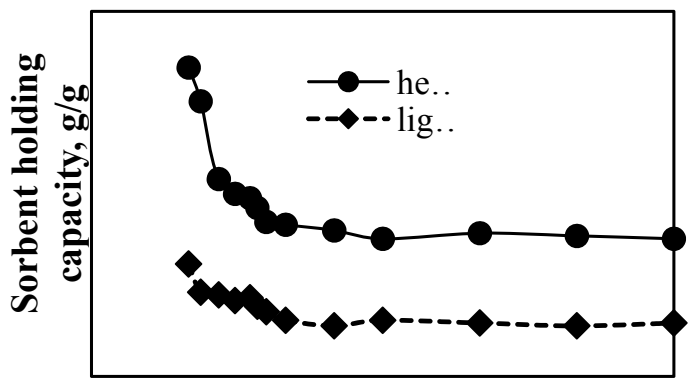

Time, min

Figure 4: Effect of desorption time on holding capacity of $\mathrm{TRH}_{700}$

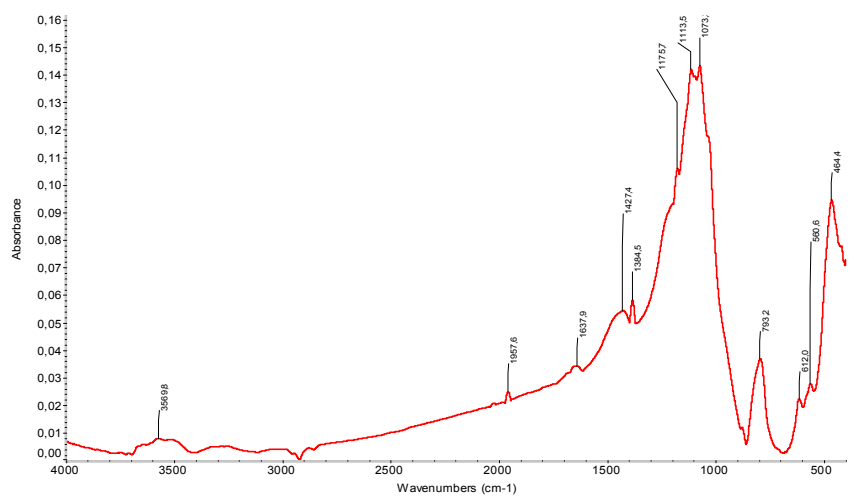

Figure 5a: FTIR spectrum of $\mathrm{TRH}_{700}$. 
Citation: Kudaybergenov KK, Ongarbayev EK, Mansurov ZA (2015) Oil Sorption by Heat-Treated Rice Husks. J Pet Environ Biotechnol 6: 243. doi:10.4172/2157-7463.1000243

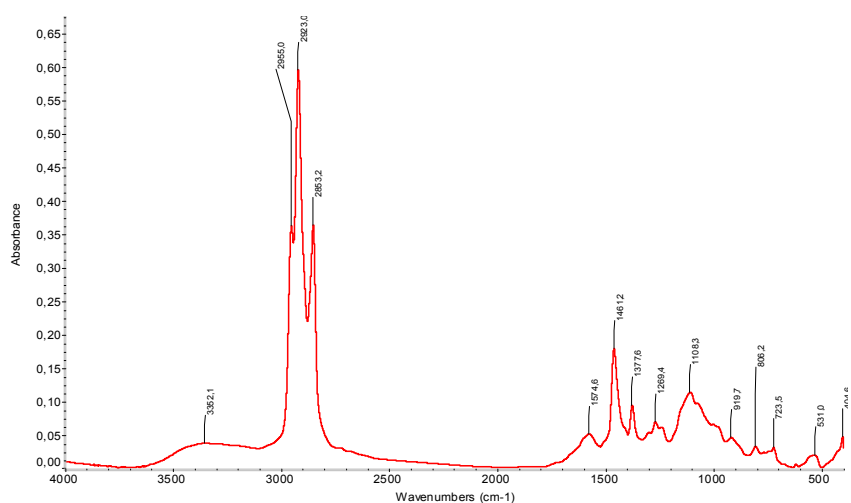

Figure 5b: FTIR spectrum of $\mathrm{TRH}_{700}$ after oil adsorption.

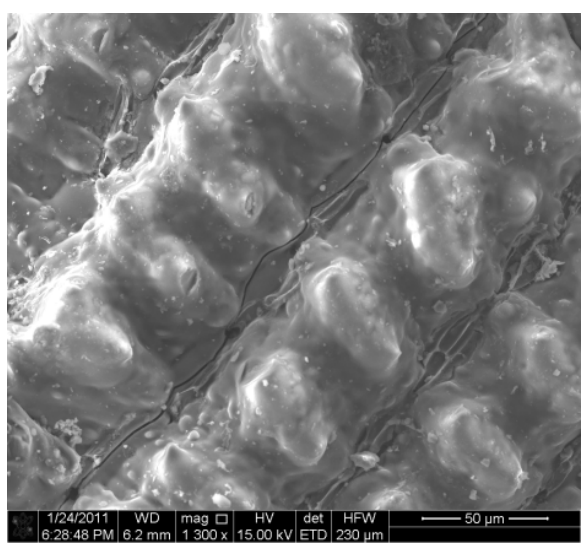

Figure 6a: SEM images of rice husk heat-treated at $700^{\circ} \mathrm{C}$ : outer epidermis of $\mathrm{TRH}_{700}$.

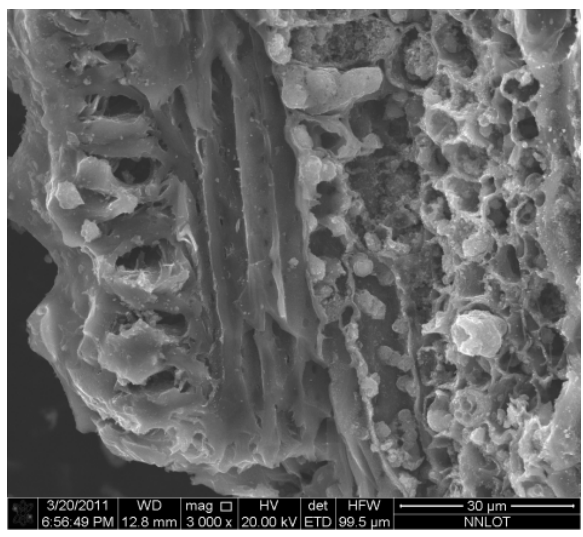

Figure 6b: SEM images of rice husk heat-treated at $700^{\circ} \mathrm{C}$ crosssections of $\mathrm{TRH}_{700}$.

\section{Conclusion}

The adsorbent obtained by thermally treated rice husks displays high efficiency and opens up possibilities for its practical application for removal of spills of crude oil and petroleum products. Results showed that the oil sorption capacities of the carbonized rice husks prepared at $700^{\circ} \mathrm{C}$ is $16 \mathrm{~g} / \mathrm{g}$ for heavy crude oil. The results of SEM images show that thermal treatment can allow one to obtain a developed structure with porosity than that of the virgin samples.

\section{References}

1. Gammoun A, Tahiri S (2007) Separation of motor oils, oily wastes and hydrocarbons from contaminated water by sorption on chrome shavings. Journal of Hazardous Materials 145: 148-153.

2. Dias J, Alvim-Ferraz MJ (2007) Waste materials for activated carbon preparation and its use in aqueous-phase treatment: A review. J Environ Manage 85: 833-846.

3. Gilpin RK, Gangodo ME, Jaroniec M (1997) Preparation and characterization of silica-carbon hybrids. Carbon 35: 133-139.

4. Maiti S, Dey S (2006) Physical and thermochemical characterization of rice husk char as a potential biomass energy source. Bioresour Technol 97: 20652070

5. Putun A, Ozbay N, Onal E, Putun E (2005) Fixed-bed pyrolysis of cotton stalk for liquid and solid products. Fuel Process. Technol 86: 1207-1219.

6. Sharma A, Rao T (1999) Kinetics of pyrolysis of rice husk. Bioresour Techno 6753-659.

7. Yakovlev V, Yeletsky P, Parmon V (2007) Preparation and investigation of nanostructured carbonaceous composites from the high-ash biomass. Chem Eng J 134: 246-255.

8. Kudaybergenov KK, Ongarbayev EK, Mansurov ZA (2010) Eurasian ChemicoTechnological Journal 12: 151-156.

9. Kudaibergenov KK, Ongarbaev EK, Mansurov ZA (2010) Proceedings of the VI International Symposium. Physics and chemistry of carbon materials Nanoengineering . Almaty 8-10: 19-122.

10. Bhattacharyya KG, Sen Gupta S (2006) Colloids and Surfaces A: Physicochemical and Engineering. Aspects 277: 191-200.

11. Hussein M, Amer AA, Sawsan (2009) Oil spill sorption using carbonized pith bagasse. Application of carbonized pith bagasse as loose fiber. Global NEST Journal 11: 440-448.

12. Inagaki M, Shibata K, Setou S, Toyoda M (2000) Sorption and recovery of heavy oils by using exfoliated graphite Part III: Trials for practical applications. Desalination 128: 219-222.

13. Choi HM, Kwon H, Moreau J (1993) Cotton nonwovens as oil spill cleanup sorbents. Text Res J 63: 211-218.

14. Daifullah AM, Girgis BS, Gad HM (2003) Utilization of agro-residues (rice husk) in small waste water treatment plans. Mater Letters 57: 1723-1731.

15. Srivastava V, Mall I, Mishra I (2006) Characterization of mesoporous rice husk ash (RHA) and adsorption kinetics of metal ions from aqueous solution onto RHA. J Hazard Mater 134: 257-267.

16. Shariff I, Ha-Ming A, Shaobin W (2009) Removal of emulsified food and mineral oils from wastewater using surfactant modified barley straw. Bioresour Technol 100: $5744-5749$. 